\title{
TRISTAN CORBIÈRE, Les Amours jaunes
}

\section{Andrea Schellino}

\section{CpenEdition \\ Journals}

\section{Édition électronique}

URL : http://journals.openedition.org/studifrancesi/16571

DOI : 10.4000/studifrancesi. 16571

ISSN : 2421-5856

\section{Éditeur}

Rosenberg \& Sellier

\section{Édition imprimée}

Date de publication : 1 juillet 2019

Pagination : 179-180

ISSN : 0039-2944

\section{Référence électronique}

Andrea Schellino, « TrISTAN Corbière, Les Amours jaunes », Studi Francesi [En ligne], 187 (LXIII | I) | 2019, mis en ligne le 01 juillet 2019, consulté le 25 janvier 2021. URL : http://journals.openedition.org/ studifrancesi/16571; DOI : https://doi.org/10.4000/studifrancesi.16571

Ce document a été généré automatiquement le 25 janvier 2021.

\section{(c) (†)}

Studi Francesi è distribuita con Licenza Creative Commons Attribuzione - Non commerciale - Non opere derivate 4.0 Internazionale. 


\title{
TRISTAN CORBIÈRE, Les Amours jaunes
}

\author{
Andrea Schellino
}

\section{RÉFÉRENCE}

TRISTAN CORBIÈRE, Les Amours jaunes, présentation, notes, dossier, glossaire, chronologie, bibliographie par Jean-Pierre Bertrand, Paris, Gallimard, 2018, «GF», 385 pp.

1 À en juger par l'effervescence éditoriale de l'année dernière, l'œuvre de Tristan Corbière, ce poète «en chair et en os tout bêtement», comme Verlaine l'écrit dans Les Poètes maudits en 1884, fait aujourd'hui l'objet d'un intérêt critique renouvelé, qui prend le relais des travaux de Jean-Luc Steinmetz, auteur, en 2011, d'une biographie parue chez Fayard: Tristan Corbière. Une vie à peu près. Ainsi récemment, en mars 2018, Yann Mortelette a dirigé un numéro de la Revue d'histoire littéraire de la France rassemblant les actes du colloque Tristan Corbière en son temps, tenu à Brest, à l'Université de BretagneOccidentale, les 3 et 4 mars 2017. L'édition des Amours jaunes établie par Jean-Pierre Bertrand illustre admirablement ce nouvel élan des recherches corbériennes. La «Présentation» (pp.5-49) situe l'esthétique de Corbière dans son temps: c'est une esthétique qui «s'inscrit dans une filiation résolument rebelle» (p. 9), voire maudite, et qui profite de «l'autonomisation de plus en plus forte de l'institution littéraire» (p. 10). Jean-Pierre Bertrand souligne à juste titre les procédés parodiques et métapoétiques de Corbière, ainsi que les tensions oxymoriques qui parcourent Les Amours jaunes, dont l'auteur fut toujours "dominé et mené par le démon de la contradiction», selon Remy de Gourmont (p.322). Le titre du recueil suggère la paronomase amour--humour: «L'humour et le rire sont étroitement solidaires d'un même acte de langage. L'humour institue une posture d'énonciation en retrait et dédoublée par laquelle le sujet divise et théâtralise son identité» (p.39). Le «Dossier» en annexe du volume (pp.307-343), consacré à la fortune des Amours jaunes, de même que la riche annotation des poèmes de Corbière, particulièrement attentive à leurs particularités réflexives et énonciatives, jettent une lumière nouvelle sur le recueil, en le rendent accessible aussi à un public d'étudiants. Jean-Pierre Bertrand propose enfin un «Petit glossaire pour servir à l'intelligence des Amours jaunes» (pp.345-365), répertoriant les termes rares, 
techniques, argotiques ou régionaux, qui font le charme heurté du vocabulaire de Corbière. 